\title{
PENGARUH PELATIHAN DAN AUDIT SUMBER DAYA MANUSIA TERHADAP PRODUKTIVITAS KERJA KARYAWAN PADA PT. SUSHI TEI INDONESIA CABANG GANDARIA CITY
}

\author{
Moh. Faisal Muttaqin ${ }^{1}$, Aden Prawiro Sudarso ${ }^{2}$ \\ Universitas Pamulang, Tangerang, Banten, Indonesia \\ ${ }^{1}$ mohfaisalmuttaqin@gmail.com, ${ }^{2}$ aden.prawiro@gmail.com
}

\begin{abstract}
This study aims to determine the effect of HR training and audits on employee work productivity either partially or simultaneously at PT. Sushi Tei Indonesia, Gandaria City Branch. The analysis method used in this research is validity test, reliability test, classical assumption test, descriptive analysis, simple linear regression test, multiple linear regression test, correlation coefficient test, determination coefficient test, $t$ test and fest. The population in this study were employees of PT. Sushi Tei Indonesia, Gandaria City Branch. Using a saturated sample of 91 respondents. The results of this study based on the coefficient of determination show that HR training and auditing have contributed to employee work productivity by $36.9 \%$ while the remaining $63.10 \%$ are other variables not examined. The results showed the multiple linear regression equation $Y=22,750+0.139(X 1)+0.445(X 2)$, meaning that even is a positive influence between (X1) and (X2) variables, employees still have a work productivity level of 22,750. The results showed that partially the training variable did not have a significant effect on employee work productivity by showing the results of the test tcount $=1.023$ while ttable $=1.98729$ (tcount <ttable) with a significance level of 0.309. partially the HR audit variable has a significant effect on employee work productivity by showing the results of tcount $=3.144$ while ttable $=1.98729$ (tcount> ttable) with a significance level of 0.002. The results of testing the simultaneous effect of independent variables on the dependent variable obtained the value of Fcount $=22.712>$ Ftable value $=3.10$, so that $\mathrm{HO}$ is rejected and Ha is accepted. So it can be concluded that there is a significant influence between training and HR audits on the work productivity of the employees of PT. Sushi Tei Indonesia, Gandaria City Branch.
\end{abstract}

Keywords : Training, HR Audit and Employee Productivity

\begin{abstract}
ABSTRAK
Penelitian ini bertujuan untuk mengetahui pengaruh pelatihan dan audit SDM terhadap produktivitas kerja karyawan baik secara parsial maupun simultan pada PT. Sushi Tei Indonesia Cabang Gandaria City. Metode analisis yang digunakan dalam penelitian ini adalah uji validitas, uji reliabilitas, uji asumsi klasik, analisis deskriptif, uji regresi linear sederhana, uji regresi linear berganda, uji koefisien korelasi, uji koefisien determinasi, Uji t dan Uji f. Populasi dalam penelitian ini adalah karyawan PT. Sushi Tei Indonesia Cabang Gandaria City. Menggunakan sampel jenuh yaitu sebanyak 91 responden. Hasil penelitian ini berdasarkan koefisien determinasi menunjukan bahwa pelatihan dan audit SDM mempunyai konstribusi terhadap produktivitas kerja karyawan sebesar 36,9\% sedangkan sisanya 63,10\% adalah variabel lain yang tidak diteliti. Hasil penelitian menunjukan persamaan regresi linear berganda $\mathrm{Y}=22,750+0.139(\mathrm{X} 1)$ $+0.445(\mathrm{X} 2)$, artinya terdapat pengaruh yang positif antara X1 dan X2 dengan karyawan tetap memiliki tingkat produktivitas kerja sebesar 22,750. Hasil penelitian menunjukan bahwa, secara parsial variabel pelatihan tidak berpengaruh signifikan terhadap produktivitas kerja karyawan dengan menunjukan hasil uji thitung = 1,023 sedangkan ttabel = 1,98729 ( thitung < ttabel ) dengan taraf signifikansi 0,309. secara parsial variabel audit SDM berpengaruh signifikan terhadap produktivitas kerja karyawan dengan menunjukan hasil thitung $=3,144$ sedangkan ttabel $=1,98729$ (thitung > ttabel) dengan taraf signifikansi 0,002. Hasil pengujian pengaruh simultan variabel bebas terhadap variabel terikatnya diperoleh nilai nilai Fhitung $=22,712>$ nilai Ftabel $=3,10$, sehingga H0 ditolak dan Ha diterima. Sehingga dapat disimpulkan bahwa terdapat pengaruh yang signifikan antara pelatihan dan audit SDM terhadap produktivitas kerja karyawan PT. Sushi Tei Indonesia Cabang Gandaria City.
\end{abstract}

Kata Kunci: Pelatihan, Audit SDM dan Produktivitas Kerja Karyawan

\section{PENDAHULUAN}

Pertumbuhan ekonomi digital dan perkembangan bisnis e-commerce tidak terlepas dari kemajuan teknologi di Indonesia. Kemajuan teknologi saat ini tidak hanya dimanfaatkan oleh sebagian orang sekedar 
untuk mencari informasi, namun lebih dari itu. Akibat dari perkembangan yang terjadi adalah penyebaran arus informasi yang cepat dan tidak terkendali. Serta perilaku sebagian masyarakat yang cenderung konsumtif akan suatu perkembangan menjadikan alasan mengapa bisnis e-commerce di Indonesia akan terus mengalami perubahan. Berbicara mengenai industri e-commerce, tidak hanya semata-mata membicarakan jual beli barang atau jasa via internet saja. Tetapi terdapat efek lain dari proses dan pengalaman jual beli tersebut.

Dengan demikian, pertumbuhan ekonomi digital dan kemajuan teknologi serta perilaku masyarakat akan memiliki dampak bagi seluruh pelaku bisnis tidak terkecuali pelaku bisnis food and service di Indonesia. Feedback dari penyebaran informasi digital dari pengalaman bersantap sebagian masyarakat akan menjadi dampak yang menakutkan bagi pelaku bisnis.

Tabel 1 Data Realisasi Target Penjualan PT. Sushi Tei Indonesia Cabang Gandaria City

\begin{tabular}{|c|c|c|c|c|}
\hline \multirow{2}{*}{ Tahun } & \multicolumn{2}{|c|}{ Realisasi Target Dan Pencapaian } & \multirow{2}{*}{ Keterangan } \\
\cline { 2 - 4 } & Target & Pencapaian & Presentase & \\
\hline 2016 & 23.975 .445 .566 & 23.267 .366 .650 & $97,00 \%$ & Tidak Mencapai Target \\
\hline 2017 & 24.132 .146 .550 & 24.025 .533 .500 & $99,60 \%$ & Tidak Mencapai Target \\
\hline 2018 & 25.015 .472 .000 & 24.314 .543 .680 & $97,10 \%$ & Tidak Mencapai Target \\
\hline 2019 & 25.615 .860 .000 & 24.615 .274 .000 & $95,90 \%$ & Tidak Mencapai Target \\
\hline
\end{tabular}

Dapat dilihat berdasarkan informasi pada tabel 1 diatas, dari hasil pencapaian target perusahaan periode tahun 2016-2019 pencapaian penjualan secara konsisten tidak dapat mencapai target hingga $100 \%$. Hal ini menunjukan produktivitas karyawan terbilang masih cukup rendah, dengan tidak tercapainya target yang telah ditentukan oleh perusahaan. Penurunan produktivitas kerja karyawan PT. Sushi Tei Indonesia tidak terjadi dengan begitu saja, terdapat beberapa penyebab yang menjadikan penurunan produktivitas kerja karyawan, salah satu faktor yang dominan adalah berasal dari dalam diri karyawan itu sendiri.
Dalam kegiatannya organisasi atau perusahaan harus mampu meningkatkan produktivitas dari waktu ke waktu, karena ini menyangkut terhadap produktivitas lembaga tersebut. Produktivitas yang baik mampu menunjukkan jumlah pencapaian yang meningkat dan memenuhi kualitas pekerjaan yang baik, mampu melakukan tindakan yang mampu menunjang pekerjaan secara optimal, memiliki kepercayaan diri yang baik dalam menyelesaikan pekerjaan, bertanggung jawab sepenuhnya pada tugas dan kewajibannya.

Disamping itu karyawan juga memiliki kemampuan dalam mengatasi persoalan dalam pekerjaan sehingga mampu menambah daya saing perusahaan secara baik. Produktivitas karyawan dapat dikatakan sangat baik jika hasil penjualan dapat mencapai atau melampaui dari realisasi target penjualan nyang diberikan oleh perusahaan. 
dijalanklan dengan baik, perusahaan sangat penting untuk melakukan evaluasi dan audit SDM.

Menurut Gaol (2019:671) yang mengemukanan audit adalah "kegiatan pemeriksaan terhadap suatu kesatuan ekonomi yang dilakukan seseorang atau kelompok/lembaga independen yang bertujuan untuk mengevaluasi atau mengukur lembaga/perusahaan dalam melaksanakan tugas atau pekerjaan dengan kriteria yang telah ditentukan”. Berikut data tabel yang dapat menggambarkan hasil audit ekternal yang dilakukan oleh perusahaan untuk melihat ketaatan karyawan dalam menjalankan standar-standar pelayanan yang telah ditetapkan belum dapat dijalakan dan dipahami oleh karyawan PT. Sushi Tei Indonesia yang dirangkum dalam tabel berikut:

Tabel 2 Data Hasil Audit Eksternal PT. Sushi Tei Indonesia Cabang Gandaria City

\begin{tabular}{|c|c|c|c|}
\hline \multirow{2}{*}{ Tahun } & \multicolumn{2}{|c|}{$\begin{array}{c}\text { Pencapaian Hasil Audit SDM dari } \\
\text { Standart Score dan Actual Score }\end{array}$} & \multirow{2}{*}{ Keterangan } \\
\cline { 2 - 3 } & Standart Score & Actual Score & \\
\hline JAN - JUN 2017 & 100 & 77 & Tidak Tercapai \\
\hline JUL - DES 2017 & 100 & 74 & Tidak Tercapai \\
\hline JAN - JUN 2018 & 100 & 78 & Tidak Tercapai \\
\hline JUL - DES 2018 & 100 & 72 & Tidak Tercapai \\
\hline JAN - JUN 2019 & 100 & 78 & Tidak Tercapai \\
\hline JUL - DES 2019 & 100 & 76 & Tidak Tercapai \\
\hline
\end{tabular}

Sumber:Data primer diolah PT. Sushi Tei Indonesia-Gandaria City, 2020

Dari data tabel 2 di atas, tergambarkan bahwa audit SDM yang dilakukan oleh perusahaan untuk melihat apakah standarstandar yang telah ditetapkan oleh perusahaan dapat sepenuhnya dijalankan oleh karyawan. Dan audit yang telah dilaksanakan dalam kurung waktu 3 (tiga) tahun terakhir, dapat dilihat bahwa rata-rata hasil audit tidak dapat mencapai $100 \%$ dari Standart Score (SS) yang telah ditetapkan. Dan audit tersebut ratarata hanya mencapai Aktual Score (AS) kurang dari $80 \%$ saja. Hal tersebut menunjukan bahwa sebagian atau hampir seluruh karyawan belum atau tidak sepenuhnya menjalankan standar-standar yang telah ditetapkan oleh perusahaan.

Kesadaran karyawan terhadap kepatuhan akan aturan yang berlaku di perusahaan masih sangat rendah, dapat dikatakan bahwa tidak berjalanya strategi yang dirancang oleh perusahaan dalam langkah mengembangkan dan melatih karyawan untuk mencapai produktivitas yang tinggi belum dapat terlaksana secara maksimal. Untuk dapat tercapainya produktivitas PT Sushi Tei Indonesia, harus dapat melihat pencapaian pelatihan yang diberikan oleh perusahaan apakah dapat tercapai secara maksimal atau tidak. Melihat betapa pentingnya faktor SDM dalam perusahaan.

Dengan pelatihan serta strategi pengembangan yang tepat, yang diberikan oleh perusahaan yang berarti perusahaan sadar betul karyawan adalah aset yang patut untuk dibimbing dan dilindungi oleh perusahaan. Dengan pelatihan dan pengembangan yang diberikan karyawan akan sadar bahwa dirinya mampu memberikan yang terbaik kepada perusahaan. Hal ini sejalan dengan pendapat dari Rivai (2014:240) yang mengemukakan pelatihan adalah"proses secara sistematis mengubah tingkah laku pegawai untuk mencapai tujuan organisasi.

Pelatihan berkatian dengan keahlian dan kemampuan pegawai untuk melaksanakan pekerjaan saat ini'”. Pelatihan memiliki orientasi 
saat ini dan membantu pegawai untuk mencapai kehalian dan kemampuan tertentu agar berhasil dalam melaksanakan pekerjaanya dan didukung dengan kehadiran peserta yang memerlukan pelatihan.
Berikut data presentase peserta pelatihan karyawan PT Sushi Tei Indonesia Cabang Gandaria City, sebagai gambaran tingkat kehadiran pelatihan karyawan yang tersaji pada tabel 3 di bawah ini:

Tabel 3 Data Kehadiran Peserta Pelatihan PT. Sushi Tei Indonesia Cabang Gandaria City Tahun 2015-2019

\begin{tabular}{|c|c|c|c|c|c|c|}
\hline \multirow{2}{*}{ Tahun } & \multirow{2}{*}{$\begin{array}{c}\text { Jumlah } \\
\text { karyawan }\end{array}$} & \multicolumn{2}{|c|}{ Trained } & \multicolumn{2}{c|}{ Untrained } & \multirow{2}{*}{ Ket } \\
\cline { 3 - 6 } & Karyawan & Persentase (\%) & karyawan & Persentase (\%) & \\
\hline 2015 & 89 & 44 & $49,44 \%$ & 45 & $50,56 \%$ & Kurang \\
\hline 2016 & 91 & 44 & $48,35 \%$ & 47 & $51,65 \%$ & Kurang \\
\hline 2017 & 91 & 41 & $45,05 \%$ & 50 & $54,95 \%$ & Kurang \\
\hline 2018 & 92 & 52 & $56,52 \%$ & 40 & $43,48 \%$ & Cukup \\
\hline 2019 & 95 & 50 & $52,63 \%$ & 45 & $47,37 \%$ & Cukup \\
\hline
\end{tabular}

Sumber: Data primer diolah PT. Sushi Tei Indonesia-Gandaria City 2020

Mengacu pada data pada tabel 3 di atas. Rata-rata pelatihan yang dilakukan oleh perusahaan selama 5 (lima) tahun menunjukan persentase kehadiran karyawan belum dapat tercapai hingga $100 \%$. Dan hal ini dapat dikatakan bahwa pelatihan yang dilakukan oleh perusahaan tidak berjalan dengan baik, sehingga disinyalir menjadi salah satu penyebab dan dampak bagi kemajuan organisasi.

Tanpa pelatihan yang baik, karyawan akan sulit untuk mencapai hasil yang optimal. Serta tindakan tidak disiplin (Indisipliner) dalam menghadiri pelatihan yang disediakan oleh perusahaan akan berdampak pada pertumbuhan organisasi perusahaan. Pelatihan dikatakan juga sebagai sarana untuk melatih dan mendidik orang-orang terhadap kemajuan dan pengembangan diri untuk dapat meyesuaikan perkembangan dan kemajuan teknologi. Perusahaan menyediakan dan membuat pelatihan SDM tentu, yang bertujuan agar dapat memenuhi target dan produktivitas kerja karyawan. Dengan tidak dipatuhi oleh karyawan pelatihan dengan baik menunjukan ketidaktaatan karyawan terhadap program-program yang telah disediakan oleh perusahaaan.

\section{METODOLOGI PENELITIAN}

Penelitian ini dilaksanakan di PT. Sushi Tei Indonesia Cabang Gandaria City yang beralamat di Jalan Sulatan Iskandar Muda, Mall Gandaria City, Lantai UG Unit 22-23, Kebayoran Lama, Jakarta Selatan. Adapun waktu penelitian dilaksanakan kurang lebih selama 4 bulan hingga tercukupi kebutuhan data dan informasi yang dibutuhkan oleh peneliti, yaitu terhitung pada bulan September - Desember 2020.

Dalam penelitian ini peneliti menggunakan sampling jenuh. Menurut Sugiyono (2017:82) berpendapat "sampling jenuh adalah teknik penentuan sampel bila semua anggota populasi digunakan sebagai sampel". Istilah lain sampel jenuh adalah sensus, dengan kata lain peneliti menggunakan seluruh populasi atau seluruh karyawan PT Sushi Tei Indonesia Cabang Gandaria City yang berjumlah 91 karyawan.

\section{HASIL DAN PEMBAHASAN \\ Pengujian Hipotesis}

\section{a. Uji Parsial (Uji T)}

Dalam penelitian ini Uji $\mathrm{t}$ digunakan untuk menguji apakah suatu nilai tertentu yang diberikan sebagai pembanding, berbeda secara nyata atau tidak dengan rata-rata sebuah sampel: 
Tabel 4 Hasil Uji Parsial (Uji T)

\begin{tabular}{|c|c|c|c|c|c|c|c|c|}
\hline \multicolumn{9}{|c|}{ Coefficients $^{\mathrm{a}}$} \\
\hline & & \multicolumn{2}{|c|}{$\begin{array}{l}\text { Unstandardized } \\
\text { Coefficients }\end{array}$} & \multirow{2}{*}{$\begin{array}{c}\text { Standardized } \\
\text { Coefficients } \\
\text { Beta }\end{array}$} & \multirow[b]{2}{*}{$\mathrm{t}$} & \multirow[b]{2}{*}{ Sig. } & \multicolumn{2}{|c|}{$\begin{array}{l}\text { Collinearity } \\
\text { Statistics }\end{array}$} \\
\hline \multicolumn{2}{|c|}{ Model } & $\mathrm{B}$ & Std. Error & & & & Tolerance & VIF \\
\hline \multirow[t]{3}{*}{1} & (Constant) & 22.750 & 5.075 & & 4.482 & .000 & & \\
\hline & Pelatihan & .139 & .136 & .154 & 1.023 & .309 & .316 & 3.163 \\
\hline & Audit SDM & .445 & .142 & .474 & 3.144 & .002 & .316 & 3.163 \\
\hline
\end{tabular}

\section{Sumber : Output SPSS Versi 25. Data diolah}

Berdasarkan tabel diatas dapat diformulasikan dalam model persamaan dengan rumus berikut :

$$
\begin{aligned}
& \mathrm{t}_{\text {tabel }}=(\mathrm{a} / 2 ; \mathrm{n}-\mathrm{k}-1 \text { atau df residual }) \\
& \mathrm{t}_{\text {tabel }}=(0,05 / 2 ; 91-2-1) \\
& \mathrm{t}_{\text {tabel }}=(0,025 ; 88) \\
& \mathrm{t}_{\text {tabel }}=1,98729
\end{aligned}
$$

Berdasarkan output pada tabel 4.20 hasil Uji t diatas, diketahui bahwa nilai koefisien regresi variabel independen yaitu Pelatihan dan Audit Sumber Daya Manusia sebagai berikut :

\section{Pelatihan Terhadap Produktivitas Kerja Karyawan (Y)}

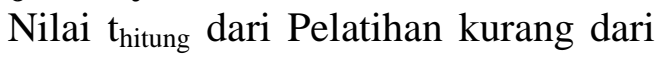
nilai $t_{\text {tabel }}$ atau $\left(1,023<t_{\text {tabel }} 1,98729\right)$ dengan nilai signifikansi 0,309 yang artinya bahwa nilai ini lebih dari tingkat signifikansi $(0,309$ $>$ 0,05). Maka dapat disimpulkan bahwa secara parisal Pelatihan berpengaruh signifikan terhadap Produktivitas Kerja Karyawan. Hal ini berarti bahwa Hol diterima dan Ha1 ditolak.

\section{Audit Sumber Daya Manusia Terhadap} Produktivitas Kerja Karyawan (Y)

Nilai $t_{\text {hitung dari Audit Sumber Daya }}$ Manusia lebih tinggi dari nilai $t_{\text {tabel }}$ atau $\left(3,144>t_{\text {tabel }} 1,98729\right)$ dengan nilai signifikansi 0,002 yang artinya bahwa nilai ini kurang dari tingkat signifikansi $(0,002<$ 0,05). Maka dapat disimpulkan bahwa secara parisal Audit Sumber Daya Manusia berpengaruh signifikan terhadap Produktivitas Kerja Karyawan. Hal ini berarti bahwa $\mathrm{Ha} 2$ diterima dan Ho2 ditolak..

\section{b. Uji Secara Simultan (Uji F)}

Uji $F$ digunakan untuk menguji pengaruh variabel independen yaitu Pelatihan dan Audit Sumber Daya Manusia secara simultan atau serentak terhadap variabel dependen yaitu Produktivitas Kerja Karyawan dengan membandingkan antara nilai $F_{h i t u n g}$ dengan $\mathrm{F}_{\text {tabel }}$.

Rumus F tabel yaitu :

$(\mathrm{df}=\mathrm{k}-1)=\mathrm{df} 1=3-1=2$ dan $(\mathrm{df} 2=\mathrm{n}-\mathrm{k})=$ $91-3=88$

Dengan signifikansi $5 \%$ atau 0,05 diperoleh $\mathrm{F}_{\text {tabel }}=\mathbf{3 , 1 0}$ dari tabel statistik. Berikut adalah hasil uji ANOVA atau uji $\mathrm{F}$ :

Tabel 5 Hasil Uji Simultan (Uji F)

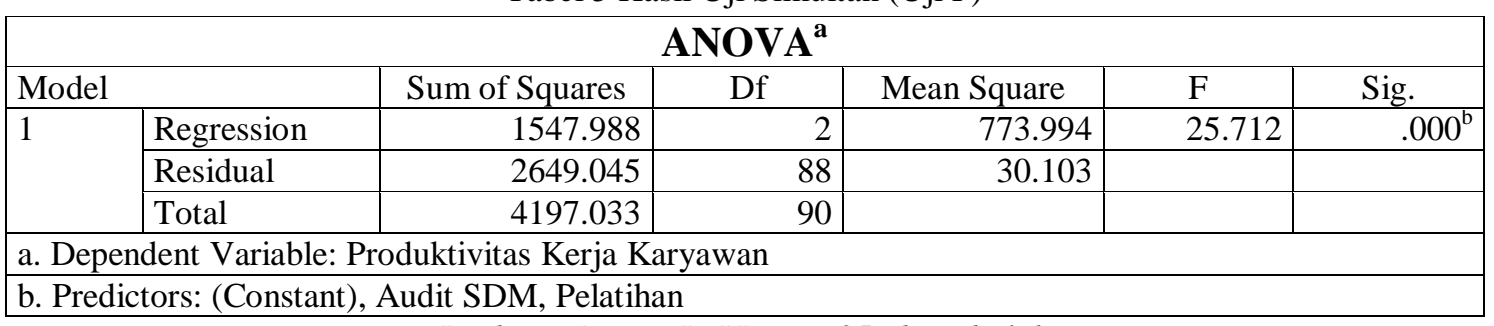

Sumber : Output SPSS Versi 25, data diolah.

Berdasarkan Output tabel 4,21, hasil uji Anova diatas diperoleh nilai $F_{\text {hitung }} \mathbf{2 5 , 7 1 2}$ lebih besar dari $\mathrm{F}_{\text {tabel }}$ dengan signifikan $\mathbf{0 , 0 0 0}$ lebih kecil dari $\mathbf{0 , 0 5}$ atau $\left(\mathrm{F}_{\text {hitung }}>\mathrm{F}_{\text {tabel }}\right)$ dan $\left(\mathrm{F}_{\text {signifikan }}<0,05\right)$. Sehingga dapat disimpulkan bahwa secara simultan Pelatihan dan Audit 
Sumber Daya Manusia secara bersama-sama berpengaruh signifikan terhadap Produktivitas Kerja Karyawan.

Berdasarkan hasil pengolahan data dan penelitian mengenai Pengaruh Pelatihan dan Audit Sumber Daya Manusia terhadap Produktivitas Kerja Karyawan didapat hasil sebagai berikut :

a. Pengaruh Pelatihan (X1) terhadap Produktivitas Kerja Karyawan (Y)

Berdasarkan hasil uji hipotesis diperoleh hasil Pelatihan terhadap Produktivitas Kerja Karyawan (Y) dengan nilai $t_{\text {hitung }}$ dari Pelatihan kurang dari nilai $t_{\text {tabel }}$ atau $\left(1,023>t_{\text {tabel }} 1,98729\right)$ dengan nilai signifikansi 0,309 yang artinya bahwa nilai ini lebih dari tingkat signifikansi $(0,309$ > 0,05). Maka dapat disimpulkan bahwa secara parisal Pelatihan tidak berpengaruh signifikan terhadap Produktivitas Kerja Karyawan. Hal ini berarti bahwa Hol diterima dan Hal ditolak.

b. Pengaruh Audit Sumber Daya Manusia (X2) Terhadap Produktivitas Kerja Karyawan (Y)

Berdasarkan hasil uji hipotesis diperoleh hasil Audit Sumber Daya Manusia terhadap Produktivitas Kerja Karyawan (Y) dengan nilai $t_{\text {hitung dari Audit Sumber Daya }}$ Manusia lebih tinggi dari nilai $t_{\text {tabel }}$ atau ( $\left.3,144>t_{\text {tabel }} 1,98729\right)$ dengan nilai signifikansi 0,002 yang artinya bahwa nilai ini kurang dari tingkat signifikansi $(0,002<$ 0,05). Maka dapat disimpulkan bahwa secara parisal Audit Sumber Daya Manusia berpengaruh signifikan terhadap Produktivitas Kerja Karyawan. Hal ini berarti bahwa Ha2 diterima dan Ho2 ditolak.

c. Pengaruh Pelatihan (X1) dan Audit Sumber Daya Manusia (X2) Terhadap Produktivitas Kerja Karyawan (Y)

Berdasarkan Output tabel 4.23, hasil uji Anova diatas diperoleh nilai $F_{\text {hitung }} 25,712$ lebih besar dari $\mathrm{F}_{\text {tabel }}$ dengan signifikan 0,000 lebih kecil dari 0,05 atau $\left(\mathrm{F}_{\text {hitung }}>\mathrm{F}_{\text {tabel }}\right)$ dan $\left(\mathrm{F}_{\text {signifikan }}<0,05\right)$. Sehingga dapat disimpulkan bahwa secara simultan Pelatihan dan Audit Sumber Daya Manusia secara bersama-sama berpengaruh signifikan terhadap Produktivitas Kerja Karyawan. Hal ini berarti bahwa Ha3 diterima dan Ho3 ditolak.

\section{KESIMPULAN}

Berdasarkan hasil uraian bab-bab sebelumnya, dan dari hasil analisa serta pembahasan mengenai pengaruh Pelatihan $\left(\mathrm{X}_{1}\right)$ dan Audit Sumber Daya Manusia $\left(\mathrm{X}_{2}\right)$ terhadap Produktivitas Kerja Karyawan (Y), sebagai berikut :

1. Secara parsial variabel Pelatihan tidak berpengaruh signifikan terhadap Produktivitas Kerja Karyawan dengan menunjukan hasil uji $t_{\text {hitung }}=1,023$ sedangkan $\mathrm{t}_{\text {tabel }}=1,98729\left(\mathrm{t}_{\text {hitung }}<\mathrm{t}_{\text {tabel }}\right)$ dengan taraf signifikan 0,309>0,05 maka $\mathrm{H}_{1}$ ditolak dan $\mathrm{H}_{0}$ diterima. Maka dapat ditarik kesimpulan bahwa variabel Pelatihan tidak berpengaruh signifikan terhadap Produktivitas Kerja Karyawan.

2. Secara parsial variabel Audit Sumber Daya Manusia berpengaruh signifikan terhadap Produktivitas Kerja Karyawan dengan menunjukan hasil uji $t_{\text {hitung }}=$ 3,144 sedangkan $t_{\text {tabel }}=1,98729\left(t_{\text {hitung }}>\right.$ $t_{\text {tabel }}$ ) dengan taraf signifikan 0,002 $<0,05$ maka $\mathrm{HO}_{2}$ ditolak dan $\mathrm{Ha}_{2}$ diterima. Maka dapat ditarik kesimpulan bahwa variabel Audit Sumber Daya Manusia berpengaruh signifikan terhadap Produktivitas Kerja Karyawan.

3. Secara Simultan variabel Pelatihan dan Audit Sumber Daya Manusia berpengaruh siginifikan secara simultan terhadap Produktivitas Kerja Karyawan dengan menunjukan $F_{\text {hitung }} 25,712$ lebih besar dari $F_{\text {tabel }}$ dengan signifikan 0,000 lebih kecil dari 0,05 atau $\left(\mathrm{F}_{\text {hitung }} 25,712>\mathrm{F}_{\text {tabel }} 3,10\right)$ 


$$
\text { dan }\left(\mathrm{F}_{\text {signifikan }} 0,000<0,05\right) \text {. }
$$

\section{DAFTAR PUSTAKA}

Algifari. (2015). Analisis Regresi untuk Bisnis dan Ekonomi. Yogyakarta: BPFE.

Agoes, Sukrisno. (2014). Auditing. Jakarta: Salemba Empat.

Agung Nugroho, (2012) "Strategi Jitu Dalam Memilih Metode Statistik Peneltian", Andi, Yogyakarta.

Anoraga, Panji. 2014. Psikologi Kerja. Jakarta: PT Rineka Cipta

Ardana, I Komang dkk. (2015) Manajemen Sumber Daya Manusia. Yogyakarta: Graha ilmu.

Arikunto, Suharsimi (2014). Prosedur Penelitian Suatu Pendekatan Praktek. Jakarta: Rineka Cipta.

Danang Sunyoto (2015), Manajemen Sumber Daya Manusia, CAPS.

Edi Sutrisno (2016). Manajemen Sumber Daya Manusia. Jakarta: Prenadamedia Group.

Gaol, CHR. Jimmy L, (2019). A to Z Human Capital (Manajemen Sumber Daya Manusia) Konsep, Teori, dan Pengembangan dalam Konteks Organisasi Publik dan Bisnis. Cetakan kelima Jakarta: PT. Gramedia Widiasarana.

Ghozali, Imam (2017). Aplikasi Analisis Multivariate Dengan Program SPSS. Edisi Kelima. Semarang: Badan Penerbit Undip.

Hasibuan, Malayu S.P. (2016). Manajemen Sumber Daya Manusia. Edisi Revisi. Jakarta: PT Bumi Aksara.

. (2019). Manajemen Sumber Daya Manusia. Edisi Revisi. Jakarta: PT Bumi Aksara

Hery. (2018). Auditing dan Asurans. Jakarta. Grasindo.

Mangkunegara, AA Anwar Prabu, "Manajemen Sumber Daya Manusia", Cetakan ke Sebelas, PT Remaja Rosdakarya, Bandung 2013

"Manajemen Sumber Daya Manusia", PT Remaja Rosdakarya, Bandung 2017

Miranda Q, Mone Stepanus, "Audit SDM", Cetakan ke dua belas, Univertitas Terbuka, Banten 2018

Ridwan, (2017). "Metode dan tehnik menyusun tesis". Penerbit : Alfabeta, Bandung

Robbins, Stephen. P. dan Mary Coulter. (2015) Manajemen. Jakarta: PT. Indeks Kelompok Gramedia. Jakarta.

Rivai Veithzal (2015) Manajemen Sumber Daya Manusia Untuk Perusahaan. Penerbit PT Raja Grafindo Persada, Jakarta, 2010.

Pelatihan”. Jakarta, 2014.

(2014)"Proses

Arti

Safroni Ladzi, "Manajemen dan Reformasi Pelayanan Publik dalam Konteks Birokrasi Indonesia", Aditya Media Publishing, Surabaya 2012.

Salam, Burhanuddin. 2015. Pengantar Filsafat. Jakarta: Bumi Aksara

Suherman, Wawan, "Kurikulum Berbasis Kompetensi Pendidikan Jasmani Teori dan Praktik Pengembangan", FIK UNY, Yogyakarta, 2012

Santoso, Singgih (2015). Menguasai Statistik Multivariat. Jakarta: PT Elex Media Komputindo.

Sinambela, Lijan Poltak. (2016). Manajemen Sumber Daya Manusia. Jakarta: PT Bumi Aksara 
Simamora, (2014). "Panduan Riset Dan Perilaku Konsumen", PT. Gramedia Pustaka Utama, Jakarta, 2014.

Sedarmayanti (2016), Sumber Daya Manusia dan Produktivitas Kerja, CV. Mandar Maju, Bandung.

Sugiyono (2017), "Metode Penelitian Kuantitatif Kualitatif dan R \& D", Penerbit CV. Alfabeta, Bandung, 2017.

(2017), Metode Penelitian Administrasi : dilengkapi dengan Metode R \& D, Bandung: Alfabeta

Sutrisno Edy, M.Si, (2016), "Manajemen Sumber Daya Manusia", Prenada Media Group, Jakarta

Suliyanto (2018), Metode Penelitian Bisnis untuk Skripsi, Tesis, \& Disertasi. Yogjakarta: Penerbit Andi (Anggota IKAPI).

Sudaryo, Yoyo. Aribowo, Agus. Sofianti, Nunung Ayu. (2018). Manajemen Sumber Daya Manusia, Kompensasi Tidak Langsung dan Lingkungan Kerja Fisik. Yogjakarta: Penerbit Andi (Anggota IKAPI).

Salam, Burhanuddin. (2014). Pengantar Filsafat. Jakarta: Bumi Aksara

Stonner (2014), Manajemen Sumber Daya Manusia Edisi Revsi. Jakarta: Penerbit PT. Bumi Aksara. 